Article

\title{
Antiprotozoal Activity of (E)-Cinnamic $N$-Acylhydrazone Derivatives
}

\section{Samir Aquino Carvalho ${ }^{1,4}$, Marcel Kaiser ${ }^{2}$, Reto Brun ${ }^{2}$, Edson Ferreira da Silva ${ }^{1}$ and Carlos Alberto Manssour Fraga $3,4, *$}

1 Instituto de Tecnologia em Fármacos e Farmanguinhos, Fundação Oswaldo Cruz, Rio de Janeiro, RJ 21041-250, Brazil; E-Mails: scarvalho@far.fiocruz.br (S.A.C.); edsonf@far.fiocruz.br (E.F.S.)

2 Swiss Tropical and Public Health Institute (Swiss TPH), Socinstrasse 57, Basel CH-4002, Switzerland; E-Mails: marcel.kaiser@unibas.ch (M.K.); reto.brun@unibas.ch (R.B.)

3 Laboratório de Avaliação e Síntese de Substâncias Bioativas (LASSBio), Programa de Pesquisa em Desenvolvimento de Fármacos, Instituto de Ciências Biomédicas, Universidade Federal do Rio de Janeiro, P.O. Box 68023, Rio de Janeiro, RJ 21941-902, Brazil

4 Programa de Pós-Graduação em Química, Instituto de Química, Universidade Federal do Rio de Janeiro, Rio de Janeiro, RJ 21949-900, Brazil

* Author to whom correspondence should be addressed; E-Mail: cmfraga@ccsdecania.ufrj.br; Tel.: +55-21-3938-6447; Fax: +55-21-3938-6478.

External Editor: D. Hadjipavlou-Litina

Received: 28 October 2014; in revised form: 29 November 2014 / Accepted: 1 December 2014 / Published: 5 December 2014

\begin{abstract}
A series of $14(E)$-cinnamic $N$-acylhydrazone derivatives, designed through molecular hybridization between the (E)-1-(benzo[ $d][1,3]$ dioxol-5-yl)-3-(4-bromophenyl)prop2-en-1-one and (E)-3-hydroxy- $N^{\prime}$-((2-hydroxynaphthalen-1-yl)methylene)-7-methoxy-2naphthohydrazide, were tested for in vitro antiparasitic activity upon axenic amastigote forms of Leishmania donovani and bloodstream forms of Trypamosoma brucei rhodesiense. The derivative (2E)-3-(4-hydroxy-3-methoxy-5-nitrophenyl)- $N^{\prime}-[(1 E)$ phenylmethylene]acrylohydrazide showed moderate antileishmanial activity ( $\mathrm{IC}_{50}=6.27$ $\mu \mathrm{M})$ when compared to miltefosine, the reference drug $\left(\mathrm{IC}_{50}=0.348 \mu \mathrm{M}\right)$. However, the elected compound showed an excellent selectivity index; in one case it was not cytotoxic against mammalian L-6 cells. The most active antitrypanosomal compound, the derivative (E)-N'-(3,4-dihydroxybenzylidene)cinnamohydrazide $\left(\mathrm{IC}_{50}=1.93 \mu \mathrm{M}\right)$, was cytotoxic against mammalian L-6 cells.
\end{abstract}


Keywords: antiprotozoal activity; Leishmania; Trypanosoma; N-acylhydrazone; (E)-cinnamic acid derivatives; molecular hybridization

\section{Introduction}

African sleeping sickness and leishmaniasis continue to cause significant public health problems. These parasitic diseases are responsible for a high rate of mortality and morbidity each year in tropical and subtropical countries [1].

African sleeping sickness is caused by the protozoan parasite Trypanosoma brucei exclusively in sub-Saharan Africa. The number of reported cases is decreasing and currently at less than 8000 per year but the estimated number is likely to be around 25,000 [2].

Leishmaniasis is a complex not contagious infectious disease that presents diverse clinical and epidemiological characteristics in each geographic area. The main forms of leishmaniasis are - visceral, cutaneous, and mucocutaneous. It is an endemic disease in many parts of the world and its estimated 1.3 million new cases and 20,000 to 30,000 deaths occur annually [3,4]. Drugs currently in use, such as pentavalent antimony compounds, pentamidine, miltefosine or amphotericin $\mathrm{B}$, are inadequate due to their toxicity, lack of efficacy, availability and affordability, and the inability to eliminate all parasite life cycles stages from the host [5].

In recent years, trans-cinnamic acid derivatives have attracted much attention due to their antimycobacterial [6], antimalarial [7], leishmanicidal [8] and antimicrobial activity [9]. It is often employed in the design of bioactive substances [10] due to the presence of an $\alpha, \beta$-unsaturated carbonyl moiety, which can be considered as a Michael acceptor unit, as the pharmacophoric group.

Recently, we reported the synthesis and trypanocidal profile of new (E)-cinnamic $N$-acylhydrazones (NAH). These derivatives were evaluated against both amastigote and trypomastigote forms of Trypanosoma cruzi and lead us to identify two compounds that were approximately two times more active than the reference drug, i.e., benznidazole, and present with good selectivity index [11].

Trypanosoma sp. and Leishmania sp. are protozoan parasites of the order kinetoplastida. Although they're different kinetoplastid pathogens have a similar genomic organization and cellular structures [12]. This evolutionary resemblance and the previous results obtained by our research group with $T$. cruzi encouraged us to evaluate a series of fourteen of these derivatives upon axenic amastigote forms of Leishmania donovani and also against bloodstream forms of Trypanosoma brucei.

The new $(E)$-cinnamic $N$-acylhydrazones were designed by molecular hybridization of two potent inhibitors cysteinyl proteases; the functionalized chalcone 1 [13], a potent inhibitor of cruzipain $\left(\mathrm{IC}_{50}=20 \mu \mathrm{M}\right)$, and the bis-naphthyl- $N$-acylhydrazone compound 2 [14], a potent inhibitor of $L$. major cathepsin L-like cysteine protease ( $\mathrm{IC}_{50}=0.5 \mu \mathrm{M}$ ) (Figure 1), to thereby enhance the inhibitory profile of the target enzyme by offering another electrophilic group capable to interact with the nucleophilic cysteine residue at the active site of the protozoan protease. 
Figure 1. Design concept of cinnamic $N$-acylhydrazone derivatives (3-16).

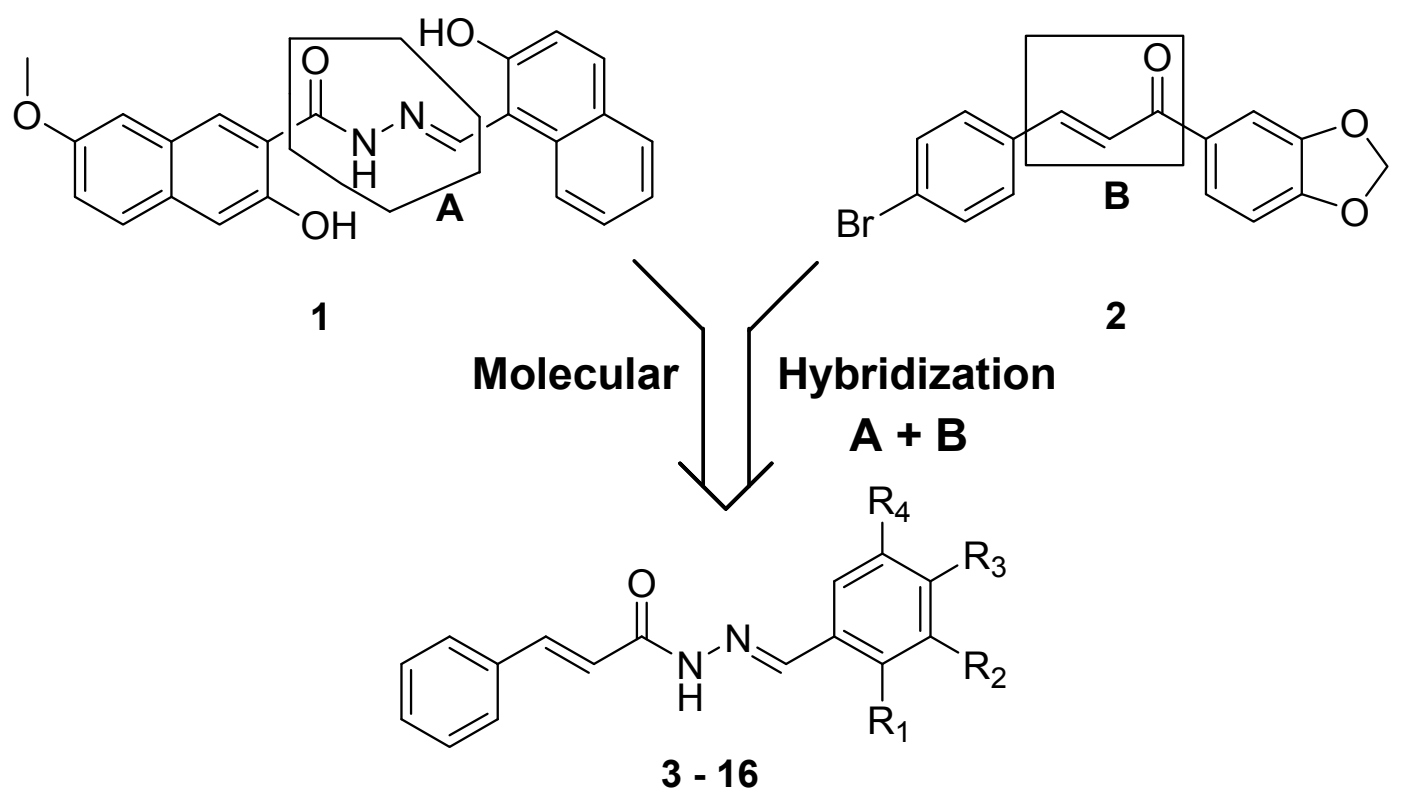

\section{Results and Discussion}

The title compounds (3-16) were prepared in good yields following the synthetic methodology previously described by our research group to access this kind of $\alpha, \beta$-unsaturated- $N$-acylhydrazones (see Table 1) [11].

The relative configuration $(E)$ for both olefine and imine double bonds was confirmed by X-ray diffraction data obtained for the unsubstituted derivative (12) [15] and also for the 4-chlorophenyl (11) and 2-hydroxyphenyl (15) derivatives [16,17]. After the careful structural characterization by ${ }^{1} \mathrm{H}-$ and ${ }^{13} \mathrm{C}$-NMR and mass spectrometry, followed by determination of a purity degree $>99 \%$ by reversed phase HPLC and elemental analysis [11], all the fourteen cinnamic $N$-acylhydrazone derivatives (3-16) were submitted to the evaluation of their antiprotozoal profile in vitro.

The antileishmanial, antitrypanosomal and cytotoxic properties of NAH derivatives (3-16) are shown in Table 1, and their respective IC $_{50}$ were determined.

Table 1. In vitro trypanocidal, leishmanicidal and cytotoxic activities of the cinnamic $\mathrm{N}$-acylhydrazone derivatives (3-16).<smiles>[R]c1cc(/C=N/NC(=O)/C=C/c2ccccc2)c([R])c([R])c1[R]</smiles>

$3-16$ 
Table 1. Cont.

\begin{tabular}{|c|c|c|c|c|c|c|c|c|c|}
\hline \multirow{2}{*}{ Cpd. } & \multirow{2}{*}{$\mathbf{R}_{1}$} & \multirow{2}{*}{$\mathbf{R}_{\mathbf{2}}$} & \multirow{2}{*}{$\mathbf{R}_{\mathbf{3}}$} & \multirow{2}{*}{$\mathbf{R}_{4}$} & L. donovani ${ }^{\text {a }}$ & T.b. rhod. ${ }^{\mathrm{b}}$ & Cytot. L-6 Cells ${ }^{c}$ & \multirow{2}{*}{ SI ${ }^{d}$} & \multirow{2}{*}{$\mathrm{SI}^{\mathrm{e}}$} \\
\hline & & & & & \multicolumn{3}{|c|}{$\mathrm{IC}_{50} \mathrm{f}(\mu \mathrm{M})$} & & \\
\hline 3 & $\mathrm{H}$ & $\mathrm{OMe}$ & $\mathrm{OH}$ & $\mathrm{NO}_{2}$ & 6.27 & 45.6 & $>264$ & $>42$ & $>5.8$ \\
\hline 4 & $\mathrm{H}$ & $\mathrm{OMe}$ & $\mathrm{OH}$ & $\mathrm{H}$ & 21.7 & 40.8 & 95.4 & 4.4 & 2.3 \\
\hline 5 & $\mathrm{H}$ & $\mathrm{OH}$ & $\mathrm{OH}$ & $\mathrm{H}$ & 11.7 & 1.93 & 14.0 & 1.2 & 7.3 \\
\hline 6 & $\mathrm{H}$ & $\mathrm{O}-\mathrm{C}$ & ${ }_{2}-\mathrm{O}$ & $\mathrm{H}$ & 12.5 & 89.5 & 4.3 & 0.3 & 0.05 \\
\hline 7 & $\mathrm{H}$ & $\mathrm{OMe}$ & $\mathrm{OMe}$ & $\mathrm{OMe}$ & 3.50 & 49.3 & 120 & 34.3 & 2.4 \\
\hline 8 & $\mathrm{H}$ & $\mathrm{H}$ & $\mathrm{F}$ & $\mathrm{H}$ & 24.3 & 284 & $>335$ & $>13.8$ & $>1.2$ \\
\hline 9 & $\mathrm{H}$ & $\mathrm{H}$ & $\mathrm{NO}_{2}$ & $\mathrm{H}$ & 10.6 & $>300$ & 255 & 24.1 & - \\
\hline 10 & $\mathrm{H}$ & $\mathrm{H}$ & $\mathrm{OMe}$ & $\mathrm{H}$ & 13.8 & 111 & $>321$ & 23.3 & 2.9 \\
\hline 11 & $\mathrm{H}$ & $\mathrm{H}$ & $\mathrm{Cl}$ & $\mathrm{H}$ & 10.8 & 121 & 65.5 & 6.0 & 0.5 \\
\hline 12 & $\mathrm{H}$ & $\mathrm{H}$ & $\mathrm{H}$ & $\mathrm{H}$ & 43.1 & $>300$ & 157 & 3.6 & - \\
\hline 13 & $\mathrm{H}$ & $\mathrm{H}$ & $\mathrm{OH}$ & $\mathrm{H}$ & 36.7 & 82.5 & 40.4 & 1.1 & 0.5 \\
\hline 14 & $\mathrm{H}$ & $\mathrm{OMe}$ & $\mathrm{OMe}$ & $\mathrm{H}$ & 31.2 & 67.6 & $>290$ & $>9.3$ & $>4.3$ \\
\hline 15 & $\mathrm{OH}$ & $\mathrm{H}$ & $\mathrm{H}$ & $\mathrm{H}$ & 3.61 & 6.72 & 14.9 & 4.1 & 2.2 \\
\hline 16 & $\mathrm{H}$ & $\mathrm{OH}$ & $\mathrm{OMe}$ & $\mathrm{H}$ & 33.3 & 80.1 & 48.1 & 1.4 & 0.6 \\
\hline MTS & - & - & - & - & 0.348 & - & ND & - & - \\
\hline MLSP & - & - & - & - & - & 0.003 & ND & - & - \\
\hline PPT & - & - & - & - & - & - & 0.006 & - & - \\
\hline
\end{tabular}

${ }^{a}$ Leishmania donovani (MHOM/ET/67/L82) axenic amastigotes [18]; ${ }^{\text {b }}$ Trypanosoma brucei rhodesiense (STIB900) [19,20]; c Cytotoxicity to L-6 rat myoblast cells [20]; ' Selectivity Index for leishmanicidal activity; e Selectivity Index for trypanocyde activity; ${ }^{\mathrm{f}} \mathrm{IC}_{50}$ values are means of two determinations. ND = Value not determined. Reference drugs: MTS (Miltefosine); MLSP (Melarsoprol); PPT (Podophyllotoxin).

The analysis of antileishmanial results showed that among the three most active compounds (3, 7 and 15) two were trisubstitued. Compound $\mathbf{1 5}$ with an $o$-hydroxyphenyl group attached to the imine unit, was one of the most active compounds $\left(\mathrm{IC}_{50}=3.61 \mu \mathrm{M}\right)$, although it was cytotoxic to mammal's cells. This considerable antiprotozoal profile in comparison to the other derivatives could be explained by the ability of the $o$-hydroxybenzylidene $N$-acylhydrazone framework to form an electrophilic quinone methide intermediate [21] that could interact with nucleophilic sites in target enzymes of Leishmania, e.g., cysteine proteases [22,23]. The 3,4,5-trimethoxyphenyl derivative (3) and the 5-nitrovanillyl derivative (7), both presenting substituents that could act as hydrogen-bond acceptors, showed important inhibitory activity with $\mathrm{IC}_{50}=6.27 \mu \mathrm{M}$ and $3.50 \mu \mathrm{M}$, respectively. When compounds (3) and (7) are compared we could observe the importance of the nitro group for antileishmanial activity, probably to their particular redox properties [24]. When we compared the trisubstituted derivatives (3) and (7) with the corresponding disubstituted ones (4) and (14) it is evident the importance of the third substituent, i.e., nitro or methoxy groups respectively, for the leishmanicidal activity. Moreover, mono- or disubstituted $\mathrm{N}$-acylhydrazone derivatives (5), (6), (9), (10) and (11), presenting substituents in the phenyl group attached to the imine unit with different stereoelectronic properties, showed a range of leishmanicidal activity varying from 10.6 to $13.8 \mu \mathrm{M}$, supporting the evidence previously discussed about the relevance of a trisubstituted pattern for the best molecular recognition by target bioreceptor. Cinnamic $N$-acylhydrazone derivative (3) presented a good selectivity index; in one case it was not toxic against mammalian L-6 cells at the maximum concentration investigated, i.e., $264 \mu \mathrm{M}$. 
On the other hand, the most active trypanocyde compound was 3,4-dihydroxyphenyl derivative (5), which present an $\mathrm{IC}_{50}=1.93 \mu \mathrm{M}$. This remarkable activity profile in comparison to the other derivatives could be explained by the pharmacophoric character of the cathecol subunit for the trypanocidal activity [25], which can act as a radical scavenger group interfering in the redox metabolism of the parasite. This result differs from our previously work, where this derivative showed poured activity against $T$. cruzi. The $o$-hydroxyphenyl derivative (15) also presented acceptable trypanocidal activity profile, $\mathrm{IC}_{50}=6.72 \mu \mathrm{M}$, in comparison to the other $N$-acylhydrazone derivatives, and it could be explained by the inhibition of cysteinyl protease, corroborating the in vitro trypanocidal activity for this compound described earlier against amastigote and tripomastigote form of $T$. cruzi [11]. Despite to show a good inhibitory potency against Trypanosoma brucei strains compounds (5) and (15) were cytotoxic against L-6 rat myoblast cells, with an $\mathrm{IC}_{50}$ of 14.0 and $14.9 \mu \mathrm{M}$ respectively, not demonstrating an appropriate safety profile for a drug candidate.

\section{Experimental Section}

\subsection{Leishmanicidal Activity}

Amastigotes of Leishmania donovani strain MHOM/ET/67/L82 were grown in axenic culture at $37{ }^{\circ} \mathrm{C}$ in $\mathrm{SM}$ medium at $\mathrm{pH} 5.4$ supplemented with $10 \%$ heat-inactivated fetal bovine serum under an atmosphere of $5 \% \mathrm{CO}_{2}$ in air. One hundred microliters of culture medium with $10^{5}$ amastigotes from axenic culture with or without the compound to test were seeded in 96-well microtiter plates. Serial drug dilution assay using seven 3-fold dilutions covering a range from $30 \mu \mathrm{g} / \mathrm{mL}$ to $0.041 \mu \mathrm{g} / \mathrm{mL}$ and determining the 50\% inhibition concentration ( $\mathrm{IC}_{50}$ ). Each drug was tested in duplicate and each assay was repeated at least once. After $72 \mathrm{~h}$ of incubation the plates were inspected under an inverted microscope to assure growth of the controls and sterile conditions. Ten microliters of Alamar Blue (12.5 mg resazurin dissolved in $100 \mathrm{~mL}$ phosphate buffered saline) [18] were then added to each well and the plates incubated for another $2 \mathrm{~h}$. Then the plates were read in a Spectramax Gemini XS microplate fluorometer (Molecular Devices Cooperation, Sunnyvale, CA, USA) using an excitation wave length of $536 \mathrm{~nm}$ and an emission wave length of $588 \mathrm{~nm}$. Data were analyzed using the software Softmax Pro (Molecular Devices Cooperation, Sunnyvale, CA, USA). Decrease of fluorescence (=inhibition) was expressed as percentage of the fluorescence of control cultures. For the serial drug dilution assay inhibition values were plotted against the drug concentrations and $\mathrm{IC}_{50}$ values were calculated from the sigmoidal inhibition curves.

\subsection{Trypanocidal Activity}

Minimum essential medium $(50 \mu \mathrm{L})$ supplemented according to a known procedure [19] with 2-mercaptoethanol and 15\% heat-inactivated horse serum was added to each well of a 96-well microtiter plate. Serial drug dilutions were prepared covering a range from 90 to $0.123 \mu \mathrm{g} / \mathrm{mL}$. Then $10^{4}$ bloodstream forms of T. $b$. rhodesiense STIB 900 in $50 \mu \mathrm{L}$ were added to each well and the plate incubated at $37{ }^{\circ} \mathrm{C}$ under a $5 \% \mathrm{CO}_{2}$ atmosphere for $72 \mathrm{~h}$. Ten microliters of Alamar Blue (containing $12.5 \mathrm{mg}$ resazurin dissolved in $1000 \mathrm{~mL}$ distilled water) were then added to each well and incubation continued for a further 2-4 h. The Alamar Blue dye is an indicator of cellular growth and/or 
viability. The blue, non-fluorescent, oxidized form becomes pink and fluorescent upon reduction by living cells. The plate was then read in a Spectramax Gemini XS microplate fluorometer (Molecular Devices Cooperation, Sunnyvale, CA, USA) using an excitation wavelength of $536 \mathrm{~nm}$ and emission wavelength of $588 \mathrm{~nm}$ [20]. Fluorescence development was measured and expressed as percentage of the control. Data were transferred into the graphic programme Softmax Pro (Molecular Devices,) which calculated $\mathrm{IC}_{50}$ values. Melarsoprol was used as standard.

\subsection{Cytotoxicity}

Exactly $100 \mu \mathrm{L}$ RPMI 1640 medium supplemented with 1\% L-glutamine (200 mM) and 10\% fetal bovine serum containing $4 \times 10^{4}$ L-6 cells (rat skeletal myoblasts) [20] were added to each well of a 96-well microtiter plate. After $24 \mathrm{~h}$, the medium was removed from all wells and replaced by $100 \mu \mathrm{L}$ of fresh medium containing a 3-fold serial drug dilution covering a range from $200 \mu \mathrm{g} / \mathrm{mL}$ to $0.274 \mu \mathrm{g} / \mathrm{mL}$, except for the control wells. After $72 \mathrm{~h}$ of incubation $10 \mu \mathrm{L}$ of Alamar Blue $(12.5 \mathrm{mg}$ resazurin dissolved in $100 \mathrm{~mL}$ phosphate buffered saline) were added to each well and the plates were incubated for another $2 \mathrm{~h}$. Then the plates were read with a Spectramax Gemini XS microplate fluorometer as described for the leishmanicidal assay. Podophyllotoxin was used as standard drug.

\section{Conclusions}

Among the three most active antileishmanial compounds (3, 7 and 15) only the cinnamic $N$-acylhydrazone derivative (3) present an excellent selectivity index ( $>42)$ (in only one case it was not cytotoxic against L-6 rat myoblast cells). In vivo leishmanicidal efficacy of this compound is being investigated and it will be described in due course. The results obtained for the trypanocidal activity against $T$. brucei rhodesiense were not encouraging (in one case the most active $N$-acylhydrazones were cytotoxic against L-6 rat myoblast cells).

\section{Acknowledgments}

The authors thank CNPq (BR), FAPERJ (BR) and FIOCRUZ (BR) for financial support and fellowships.

\section{Author Contributions}

Conceived and designed the experiments: Carlos Alberto Manssour Fraga (C.A.M.F.), Edson Ferreira da Silva (E.F.S.), Reto Brun (R.B.). Performed the experiments: Samir Aquino Carvalho (S.A.C.), Marcel Kaiser (M.K.). Analyzed the data: C.A.M.F., E.F.S., R.B., S.A.C., M.K. Contributed reagents/materials/analysis tools: C.A.M.F., E.F.S., R.B. Wrote the paper: CAMF, EFS, SAC.

\section{Conflicts of Interest}

The authors declare no conflict of interest. 


\section{References}

1. Ndjonka, D.; Rapado, L.N.; Silber, A.M.; Liebau, E.; Wrenger, C. Natural Products as a Source for Treating Neglected Parasitic Diseases. Int. J. Mol. Sci. 2013, 14, 3395-3439.

2. WHO. Trypanossomiasis, Human African (Sleeping Sickness). Fact Sheet No259. Available online: http://www.who.int/mediacentre/factsheets/fs259/en/ (accessed on 3 October 2014).

3. Alvar, J.; Vélez, I.; Bern, C.; Herrero, M.; Desjeux, P.; Cano, J.; Jannin, J.; den Boer, M.; The WHO Leishmaniasis Control Team. Leishmaniasis worldwide and global estimates of its incidence. PLoS One 2012, 7, e35671.

4. World Health Organization (WHO). World Health Organization Technical Report 949: Control of the Leishmaniases; WHO: Geneva, Switzerland, 2010; pp. 1-186.

5. Alvar, J.; Croft, S.; Olliaro, P. Chemotherapy in the treatment and control of leishmaniasis. Adv. Parasitol. 2006, 61, 223-274.

6. Carvalho, S.A.; da Silva, E.F.; de Souza, M.V.N.; Lourenço, M.C.S.; Vicente, F.R. Synthesis and antimycobacterial evaluation of new trans-cinnamic acid hydrazide derivatives. Bioorg. Med. Chem. Lett. 2008, 18, 538-541.

7. Kanaani, J.; Ginsburg, H. Effects of cinnamic acid derivatives on in vitro growth of Plasmodium falciparum and on the permeability of the membrane of malaria-infected erythrocytes. Antimicrob. Agents Chemother. 1992, 36, 1102-1108.

8. Otero, E.; Robledo, S.M.; Diaz, S.; Carda, M.; Muñoz, D.; Paños, J.; Vélez, I.D.; Cardona, W. Synthesis and leishmanicidal activity of cinnamic esters: Structure-activity relationship. Med. Chem. Res. 2014, 23, 1378-1386.

9. Naz, S.; Ahmed, S.; Rasool, S.A.; Sayeed, S.A.; Siddiqi, R. Antibacterial activity directed isolation of compounds from Onosma hispidum. Microb. Res. 2006, 161, 43-48.

10. Ahn, B.Z.; Sok, D.E. Michael Acceptors as a Tool for Anticancer Drug Design. Curr. Pharm. Des. 1996, 2, 247-262.

11. Carvalho, S.A.; Feitosa, L.O.; Soares, M.; Costa, T.E.M.M.; Henriques, M.G.; Salomão, K.; de Castro, S.L.; Kaiser, M.; Brun, R.; Wardell, J.L.; et al. Design and synthesis of new (E)-cinnamic $\mathrm{N}$-acylhydrazones as potent antitrypanosomal agents. Eur. J. Med. Chem. 2012, 54, 512-521.

12. Stuart, K.; Brun, R.; Croft, S.; Fairlamb, A.; Gürtler, R.E.; McKerrow, J.; Reed, S.; Tarleton, R. Kinetoplastids: Related protozoan pathogens, different diseases. J. Clin. Investig. 2008, 118, 1301-1310.

13. Borchhardt, D.M.; Mascarello, A.; Chiaradia, L.D.; Nunes, R.J.; Oliva, G.; Yunes, R.A.; Andricopulo, A.D. Biochemical Evaluation of a Series of Synthetic Chalcone and Hydrazide Derivatives as Novel Inhibitors of Cruzain from Trypanosoma cruzi. J. Braz. Chem. Soc. 2010, 21, $142-150$.

14. Selzer, P.M.; Chen, X.; Chan, V.J.; Cheng, M.; Kenyon, G.L.; Kuntz, I.D.; Sakanari, J.A.; Cohen, F.E.; McKerrow, J.H. Leishmania major: Molecular modeling of cysteine proteases and prediction of new nonpeptide inhibitors. Exp. Parasitol. 1997, 87, 212-221.

15. Carvalho, S.A.; Silva, E.F.; Fraga, C.A.M.; Wardell, S.M.S.V.; Wardell, J.L.; Tiekink, E.R.T. (2E)- $N^{\prime}$-[(E)-Benzylidene]-3-phenylprop-2-enohydrazide from synchrotron radiation. Acta Crystallogr. 2012, E68, o2255-o2256. 
16. Carvalho, S.A.; Silva, E.F.; Fraga, C.A.M.; Wardell, S.M.S.V.; Wardell, J.L.; Tiekink, E.R.T. (2E)- $N^{\prime}$-[(E)-4-Chlorobenzylidene]-3-phenylprop-2-enohydrazide monohydrate. Acta Crystallogr. 2010, E66, o2410-02411.

17. Carvalho, S.A.; Silva, E.F.; Fraga, C.A.M.; Wardell, S.M.S.V.; Wardell, J.L.; Tiekink, E.R.T. (2E)- $N$ '-[(E)-2-Hydroxybenzylidene]-3-phenylprop-2-enohydrazide. Acta Crystallogr. 2012, E68, o2253-o2254.

18. Mikus, J.; Steverding, D. A simple colorimetric method to screen drug cytotoxicity against Leishmania using the dye Alamar Blue. Parasitol. Int. 2000, 48, 265-269.

19. Baltz, T.; Baltz, D.; Giroud, C.; Crockett J. Cultivation in a semi-defined medium of animal infective forms of Trypanosoma brucei, T. equiperdum, T. evansi, T. rhodesiense and T. gambiense. EMBO J. 1985, 4, 1273-1277.

20. Räz, B.; Iten, M.; Grether-Bühler, Y.; Kaminsky, R.; Brun, R. The Alamar Blue assay to determine drug sensitivity of African trypanosomes (T. b. rhodesiense and T. b. gambiense) in vitro. Acta Trop. 1997, 68, 139-147.

21. Ifa, D.R.; Rodrigues, C.R.; Alencastro, R.B.; Fraga, C.A.M.; Barreiro, E.J. A possible molecular mechanism for the inhibition of cysteine proteases by salicylaldehyde $N$-acylhydrazones and related compounds. J. Mol. Struct. Theochem. 2000, 505, 11-17.

22. Mottram, J.C.; Coombs, G.H.; Alexander, J. Cysteine peptidases as virulence factors of Leishmania. Curr. Opin. Microbiol. 2004, 7, 375-381.

23. Selzer, P.M.; Pingel, S.; Hsieh, I.; Ugele, B.; Chan, V.J.; Engel, J.C.; Bogyo, M.; Russell, D.G.; Sakanari, J.A.; Mc Kerrow, J.H. Cysteine protease inhibitors as chemotherapy: Lessons from a parasite target. Proc. Natl. Acad. Sci. USA 1999, 96, 11015-11052.

24. Wilkinson, S.R.; Bot, C.; Kelly, J.M.; Hall, B.S. Trypanocidal activity of nitroaromatic prodrugs: Current treatments and future perspectives. Curr. Top. Med. Chem. 2011, 11, 2072-2084.

25. Carvalho, S.A.; da Silva, E.F.; Santa-Rita, R.; de Castro, S.L.; Fraga, C.A.M. Synthesis and antitrypanosomal profile of new functionalized 1,3,4-thiadiazole-2-arylhydrazone derivatives, designed as non-mutagenic megazol analogues. Bioorg. Med. Chem. Lett. 2004, 14, 5967-5970.

Sample Availability: Samples of the cinnamic $N$-acylhydrazone derivatives are available from the authors.

(C) 2014 by the authors; licensee MDPI, Basel, Switzerland. This article is an open access article distributed under the terms and conditions of the Creative Commons Attribution license (http://creativecommons.org/licenses/by/4.0/). 